\author{
Monika Chuchro \\ MACIEJ DWORNIK \\ KAMIL SzOSTEK \\ ANDRZEJ LEŚNIAK
}

\title{
OPTIMAL SELECTION \\ OF NUMERICAL MODELS \\ FOR FLOOD EMBANKMENT PORE \\ PRESSURE AND TEMPERATURE DATA
}

\begin{abstract}
This article presents a method of the stability assessment of the experimental flood embankment used in the ISMOP project. Simultaneous conduction of numerical modeling using Itasca Flac 2D 7.0 software and real performed flood experiments allows for a detailed analysis of the state of flood embankment stability. The aim of the article is a presentation of similarity assessment between numerical models and a real performed flooding experiment using an aggregate moving window and L1-norm. By evaluating these similarity measures, numerical models with greater resemblance to real data from a flood embankment are chosen. On this basis, the embankment stability state is evaluated. In addition, the purpose of this article is also to present the results of the performed tests between those gathered in the database numerical models and a real flooding experiment from a full-size earthen flood embankment with built-in sensors built in Czernichow, Poland.
\end{abstract}

Keywords

Citation Computer Science 18(4) 2017: 399-412 


\section{Introduction}

Floods are one of the greatest natural hazards in Poland and occur every year on a local scale and every few years regionally. Over the past twenty years, national flooding occurred in 1997 and 2010.

A loss of embankment stability is the most-common reason why floods cause damage to areas near rivers (e.g., the Vistula River embankment in Krakow near the heat and power plant, or the Odra River in Winska in Lower Silesia). Many countries (e.g., Denmark and the Netherlands) have developed systems that monitor embankments and predict failure $[12,14,16,17]$. In Poland, this system is the Computer System for Monitoring River Embankments project (ISMOP), which is financed by the NCBiR $[2,9]$.

The objective of the ISMOP project is to monitor the state of embankments when water levels are higher than usual. To this end, experimental embankments in the shape of a stadium were built that are $4.5 \mathrm{~m}$ tall, $50 \mathrm{~m}$ wide, and $200 \mathrm{~m}$ long (Figure 1, [13]).

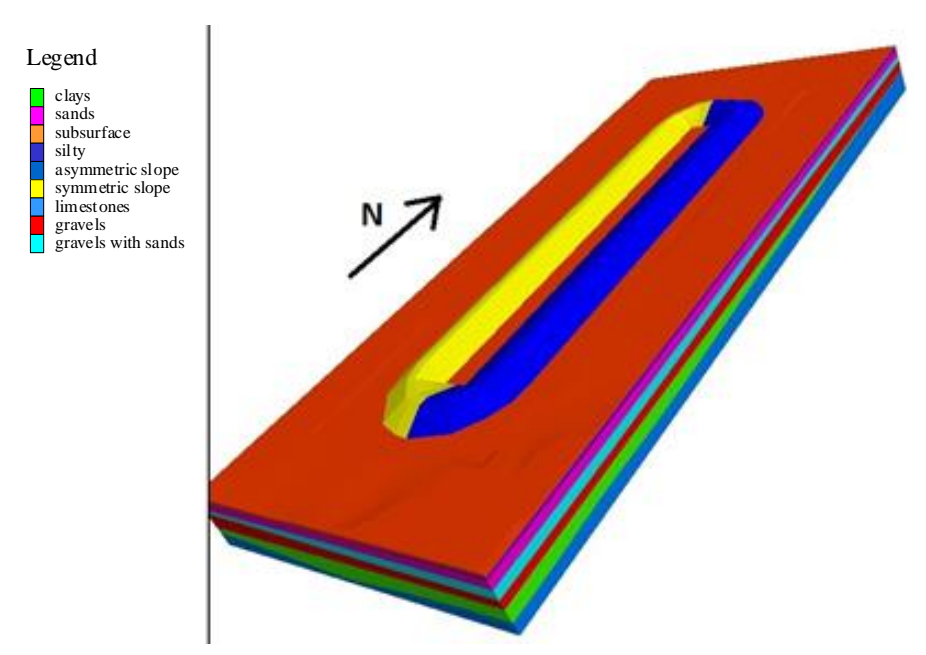

Figure 1. The shape of the experimental embankment with geological details [6].

A reservoir inside the structure is used to simulate flood waves by changing water levels. This reservoir is approximately $150 \mathrm{~m}$ long, $8 \mathrm{~m}$ wide at the bottom, and $28 \mathrm{~m}$ wide at the top. The maximum safe water level is $4 \mathrm{~m}$. The embankments contain multiple sensors that record pore pressure, temperature, and stress. The readings from these sensors are available in real time [1, 18]. A modern fiber-optic system was installed in the embankment to provide continuous passive or active temperature measurements. The monitoring system transmits data in real time to a data warehouse where it can be aggregated and analyzed in order to detect embankment instability [5]. 


\section{Numerical models}

Numerical modeling is used to estimate selected parameters using mathematical formulas and computer algorithms. Modeling can calculate the sensor values in digital embankments and simulate scenarios that would be difficult and dangerous to recreate in real life. In the ISMOP project, embankment sensor parameters are calculated for different water-level-change events. Numerical modelings use finite-difference methods (FDM) that are implemented in Itasca Flac 2D 7.0 software [10]. The model has a rectangular grid with a cell size of 0.1 by $0.1 \mathrm{~m}$, which approximates the embankments' vertical cross-sections in the east-west direction. The model of the embankment was extended by $3 \mathrm{~m}$ in depth and $20 \mathrm{~m}$ on the left and right sides, as this decreases the influence of the model edges on the calculations [15]. Displacements of the model nodes are fixed with zero value on the lower and side edges of the model to stabilize them. Additionally, the temperature is fixed at a constant value (ground temperature) on the lower edge of the model. The temperature on the upper edge is set at $1 \mathrm{~h}$ intervals to the air or water temperature (depending on the water level) $[3,11]$.

The modeling process is conducted in three stages [6]:

- ground stabilization,

- ground and embankment stabilization,

- water flow, heat transition, and stabilization calculation at $1 \mathrm{~h}$ intervals.

The modeling results are presented in Figures 2 and 3.

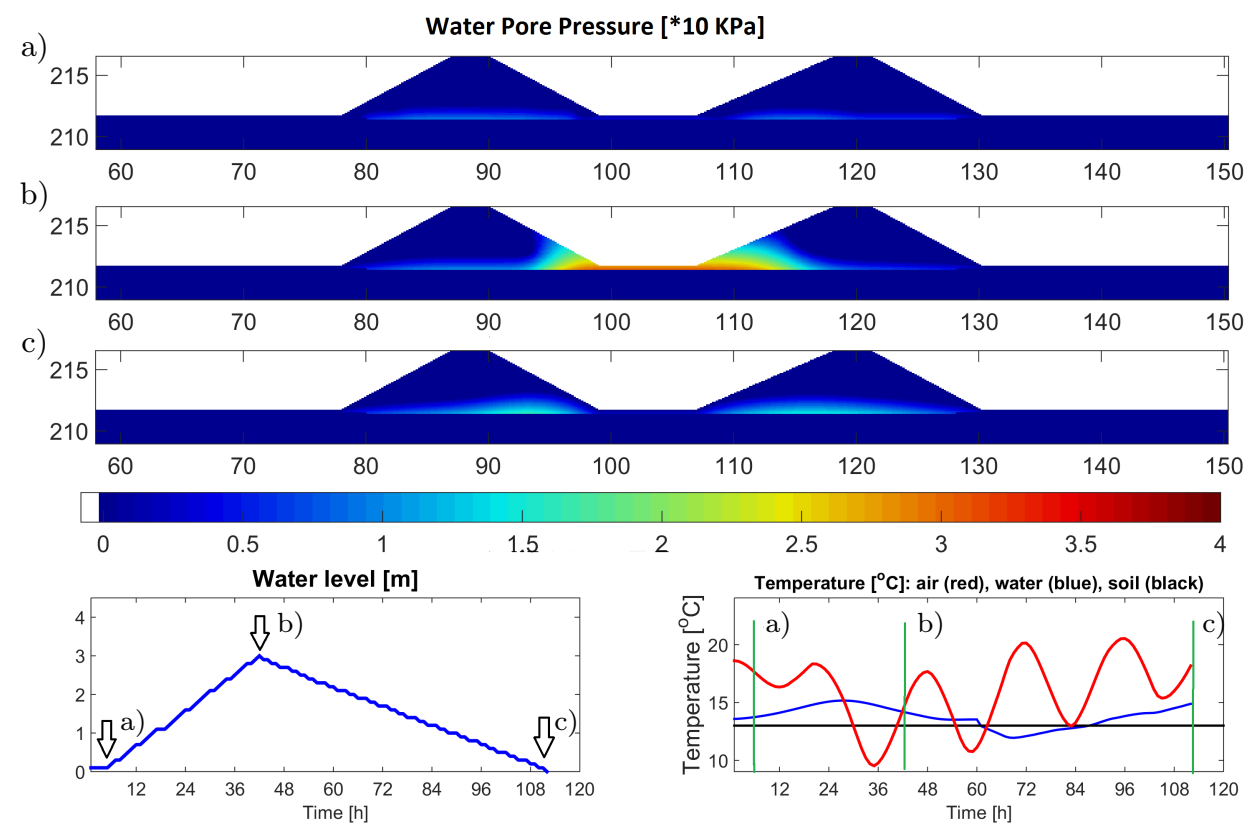

Figure 2. Distribution of pore pressure in embankment at each simulation stage. 
a)

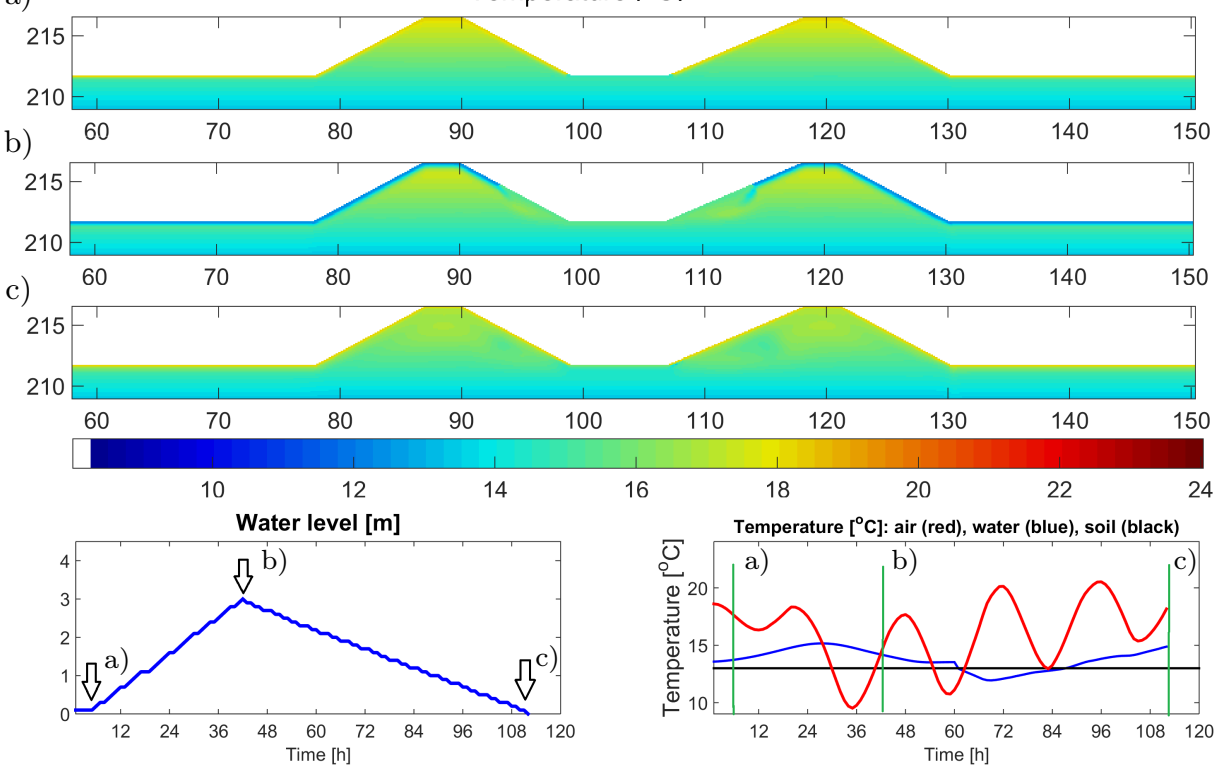

Figure 3. Distribution of temperature in embankment at each simulation stage.

Flooding was performed as a water-level rise from $0 \mathrm{~m}$ to $3 \mathrm{~m}$ over $36 \mathrm{~h}$, then a decrease to $0 \mathrm{~m}$ over $72 \mathrm{~h}$. Figures 2 and 3 show the distribution of pore pressure and temperature for each simulation stage: a) onset of water level rise $(6 \mathrm{~h}) ; \mathrm{b})$ maximum water level $(42 \mathrm{~h})$; c) return to water level of $0 \mathrm{~m}(118 \mathrm{~h})$. A comparison of the different numerical models can be found in [7].

\section{Model-driven algorithms}

A model-driven module can be used to find and match the simulated numerical models that are most-similar to the observed time series of the real embankment sensor data. The purpose of the model-driven algorithms is to predict the influence of environmental factors and estimate the probability of stability changes in the flood embankment [5].

The analysis was performed on each half cross-section of the embankment (Fig. 4). For each sensor in each half cross-section, a real-time series is uploaded to the database. Taken at 15-minute intervals, these time series initially contain 100 observations and grow longer as new sensor data is recorded from the real embankment [4].

To decrease the number of transformations and calculations, analysis starts with a calculation of Pearson's correlation matrix for each sensor time series (separately for temperature and pore-pressure data). Next, these values are multiplied, and the data for the sensors is averaged if the absolute values are greater than 0.8 . 


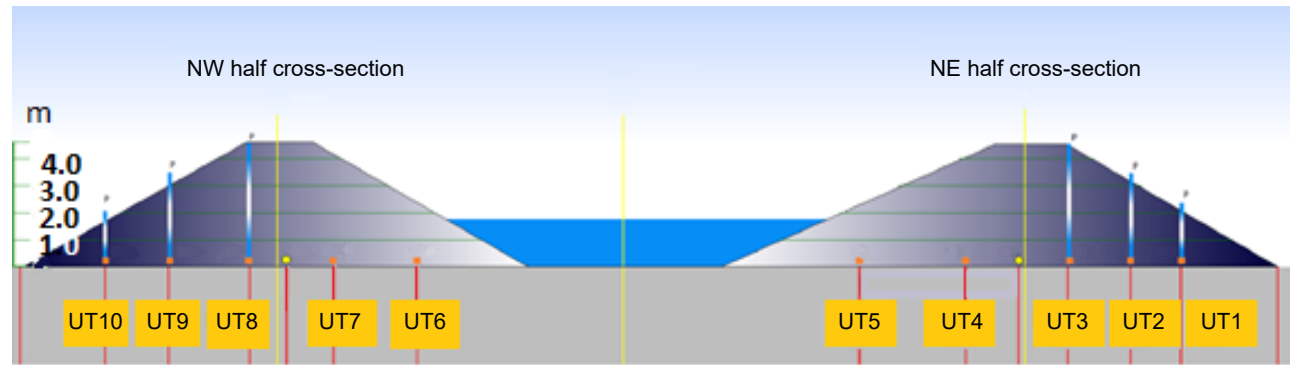

Figure 4. Cross-section of experimental embankments with half cross-sections marked, UT sensors, and piezometers (blue lines).

Subsequently, these sensor time series are compared to the simulated data from the database for the selected half cross-section. The lengths of the compared time series are not equal, as the numerical models have time series of differing lengths. Moreover, the simulated time series are averaged in the same way as the real ones. The best match is then selected in the moving window, which grows with each algorithm iteration.

The L1-norm metric was chosen for similarity evaluation measurements, and Mean Square Error (MSE) could also be used in the tests. The smaller the L1-norm and MSE are, the closer we come to finding the best-fitting numerical model for a real experiment. With an increase in L1-norm and MSE values, the resemblance between the numerical models and real experiments decrease. For each moving window, similarity metrics were calculated for temperature data and pore-pressure records. These are then multiplied or summed, and the results are shown as final similarity metrics in input data units. The lowest values are then saved with the offset of the moving window for which these results were obtained. The comparisons were calculated for all available numerical models.

$$
\begin{gathered}
L 1-\operatorname{norm}\left(x_{1}, x_{2}\right)=\frac{1}{n} \Sigma\left|x_{1_{i}}-x_{2_{i}}\right| \\
M S E\left(x_{1}, x_{2}\right)=\frac{1}{n} \Sigma\left(x_{1_{i}}-x_{2_{i}}\right)^{2}
\end{gathered}
$$

where $n$ is a size of $x$.

Numerical models were calculated with the scheme described in [6] for different scenarios (shape of flood waves) and weather conditions. After this, a ranking of the ten-best matches was created and presented [8].

The whole process can be reiterated for the next time step when new data is recorded and saved in the database. The length of each time series then increases by 1 [4]. The analysis is repeated first for the real-time series and then with simulated data. All simulations (or a limited number) can be used as required. 


\section{Test}

To test the model-driven module, a $\mathrm{C}$ application was written and compiled with Microsoft Visual $\mathrm{C}++$ (MSVC) version v120 for Windows environments and GCC version 4.8 for Linux.

As designed, the program for comparisons is a batch program. Therefore, it can easily be used for single tests or can eventually be used as a part of an embankment monitoring system from the management application (as it was originally intended). Furthermore, the presented approach allows the module to be run in parallel on multiple machines (both physical and virtual), which significantly reduces computation time and is required for real-time embankment monitoring.

The input data is served to the module as CSV files that can easily be rendered from database data. These files contain records of temperature or temperature and pore pressure, together with timestamps. Depending on the input data, the analysis is performed for the available parameters. The product of L1-norm comparisons are presented and saved together with the offset values as described above.

The test was performed for an experiment consisting of raising the water to three meters and then (without a plateau) draining it (Fig. 5). The experiment started at 9 p.m. on August 29, 2016, and ended at 9 a.m. on September 3, 2016.

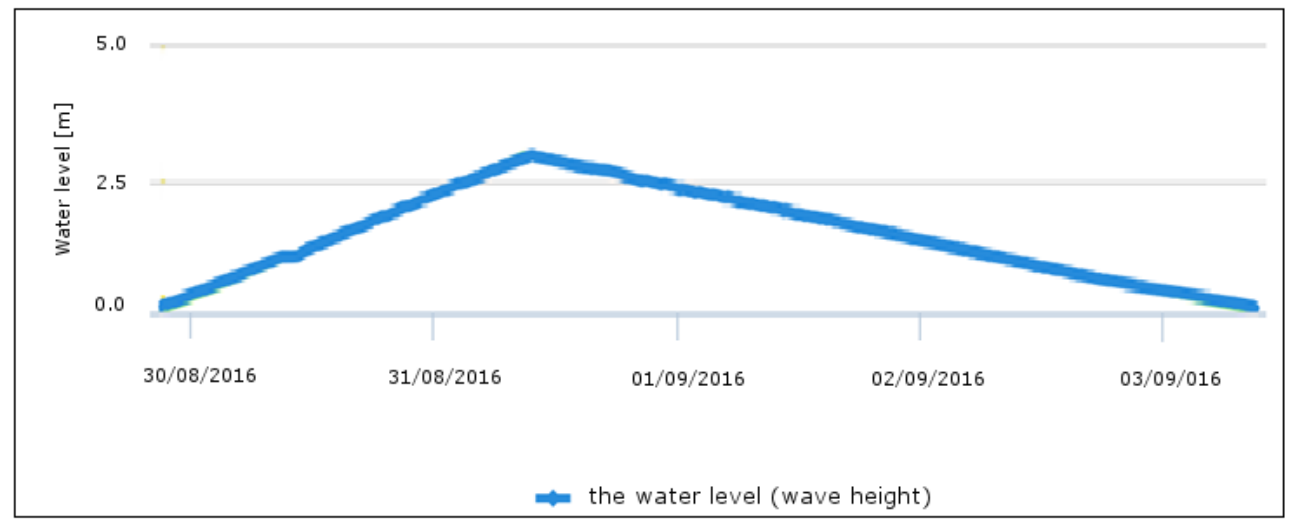

Figure 5. Water level in experimental embankment during experiment.

The NW section, which contains temperature and pore-pressure sensors marked from id UT6 to UT10, was selected for analysis. The changes of the monitored values inside the embankment are shown below (Figs. 6 and 7).

The largest variability of the parameters can be observed for pore pressure from the upstream side, and the sensors located furthest from the river present a slower reaction to water-level changes (Fig. 6). The changes recorded by the temperature sensors are minor, especially when compared to air temperature (ASP.TZ). During the experiment, a single $3^{\circ} \mathrm{C}$ drop was recorded (Fig. 7). 


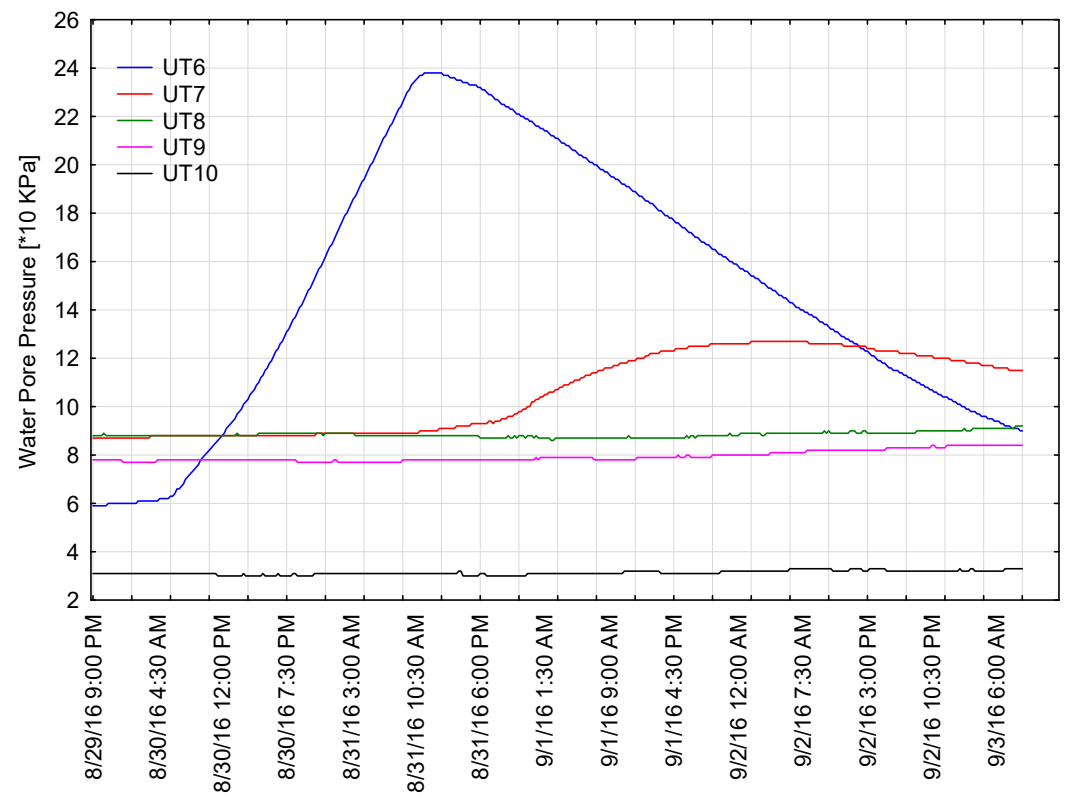

Figure 6. Pore pressure recorded in NW section of embankment during experiment.

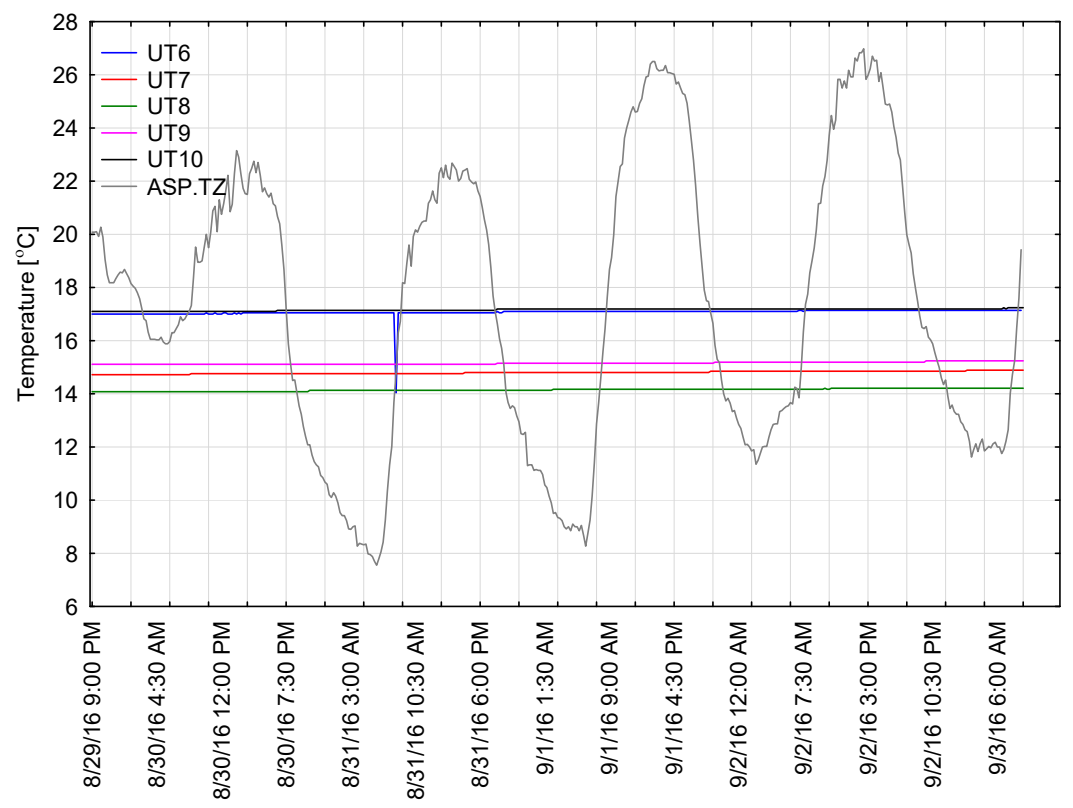

Figure 7. Temperature recorded in NW section of embankment during experiment, with air temperature (ASP.TZ). 
For the test, 17 simulated scenarios of various water-level rises and falls were used. The plateaus and initial conditions varied. During the test, four methods were used with L1-norm, multiplying L1-norm, and summing L1-norm for the real and standardized data. Table 1 shows basic information about the numerical modelings used for the tests. Modeling 3.1 reflects the real experiment conditions from August 29, 2016, through September 3, 2016.

Table 1

Numerical models parameters.

\begin{tabular}{|c|c|c|c|c|c|c|c|}
\hline $\begin{array}{c}\text { Number } \\
\text { of } \\
\text { numerical } \\
\text { model }\end{array}$ & $\begin{array}{c}\text { Numerical } \\
\text { model } \\
\text { time }[\mathrm{h}]\end{array}$ & $\begin{array}{c}\text { Water } \\
\text { rise } \\
\text { start } \\
\text { hour }[\mathrm{h}]\end{array}$ & $\begin{array}{c}\text { Water } \\
\text { riseend } \\
\text { hour }[\mathrm{h}]\end{array}$ & $\begin{array}{c}\text { Plateau } \\
\text { time }[\mathrm{h}]\end{array}$ & $\begin{array}{c}\text { Draining } \\
\text { start } \\
{[\mathrm{h}]}\end{array}$ & $\begin{array}{c}\text { Draining } \\
\text { end }[\mathrm{h}]\end{array}$ & $\begin{array}{c}\text { Water } \\
\text { level } \\
\text { height } \\
{[\mathrm{m}]}\end{array}$ \\
\hline 1.1 & 108 & 32 & 58 & 0 & 58 & 94 & 2 \\
\hline $\begin{array}{c}2.1,2.2, \\
2.3,2.4\end{array}$ & 240 & 6 & 32 & 0 & 32 & 72 & 2 \\
\hline $3.1,3.2$, & 118 & 6 & 42 & 0 & 42 & 118 & 3 \\
\hline $3.3,3.4$ & 290 & 32 & 132 & 0 & 132 & 244 & 4 \\
\hline 4.1 & 200 & 32 & 80 & 0 & 80 & 150 & 3 \\
\hline $5.1,5.2$ & 280 & 32 & 70 & 60 & 30 & 244 & 3 \\
\hline $6.1,6.2$, & & & 132 & 0 & 132 & 200 & 3 \\
\hline $6.3,6.4$ & & & & & & & \\
\hline
\end{tabular}

Modelings with equal increases and decreases in water level but with differing initial conditions have the same first id number. Few flood embankments in Poland have water pore pressure sensors, so an artificial initial condition was also tested. The initial saturation levels for modelings 1-5 were set as follows:

- n.1 - natural embankment saturation;

- n.2 - 1/6 embankment height was saturated with water;

- n.3 - 1/3 embankment height was saturated with water;

- n.4 - embankment is initially dry.

For Simulation 6, the initial conditions were set as follows:

- 6.1 - 1/4 embankment's height was saturated with water, weather conditions from forecast;

- 6.2 - $1 / 4$ embankment's height was saturated with water, bentomata;

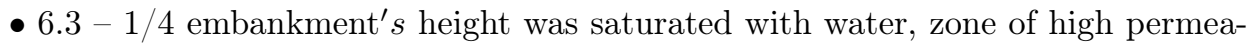
bility;

- 6.4 - natural embankment's saturation, real weather conditions.

One of the project requirements was to perform an analysis in 15-minute time steps. Therefore, the numerical models were converted from 1 hour to 15-minute time steps using linear interpolation. 
The test of the model-driven module started with a calculation of the matrix of Pearson's linear correlation for time series measurements; a high correlation between the UT7 and UT9 sensors was revealed. These measurements and the corresponding simulated sensor time series were averaged. Next, real sensor data and 17 simulated scenarios for the NW half-section were compared using L1-norm as similarity measure. Four methods were used with L1-norm, multiplying L1-norm, and summing L1-norm for the real and standardized data. At this stage of the project, numerical models have to validate the pore pressure models while the validation of the temperature models was not performed. So, multiplying the L1-norm for temperature and pore pressure could lead to selection models with a better-modeled single parameter (not always both). For this method, the three best-fitting numerical models were chosen: 6.1 (mean value of L1-norm: 140), 2.1 (mean value of L1-norm: 180), and 3.1 (mean value of L1-norm: 185). For sensor UT6 (which was closest to the water), the lowest L1-norm value was achieved for numerical modeling 6.1 (138). The difference between the first and second results of the comparison is more than 60. For sensors on the other side of the flood embankment (furthest from the water), modeling 6.1 gives the highest error (216): the best-ranked simulations are then 2.1 (165) and 3.1 (170). Data standardization does not significantly improve the results: numerical model 3.1 is one of the three best-fitting models, along with 6.1 and 6.2.

The best results were obtain for the sum of L1-norm: the same order of the tenbest numerical models were gained for both the non-standardized and standardized data. The size of the comparison window in the first iteration was set to 100 records. The results of the comparison are shown in Table 2.

Table 2

Results of similarity measure L1-norm for 10-best matches to numerical models for 100-observation window length.

\begin{tabular}{|l|c|c|c|c|}
\hline $\begin{array}{l}\text { Number } \\
\text { Numerical } \\
\text { Model }\end{array}$ & UT6 & UT7-UT9 & UT8 & UT10 \\
\hline 3.1 & 27.0 & 26.4 & 25.9 & 28.6 \\
\hline 5.1 & 29.4 & 26.9 & 26.1 & 29.0 \\
\hline 1.1 & 29.5 & 26.8 & 26.1 & 29.5 \\
\hline 6.1 & 26.9 & 27.0 & 29.1 & 31.3 \\
\hline 6.3 & 26.9 & 27.0 & 29.1 & 31.3 \\
\hline 6.2 & 27.4 & 28.5 & 27.1 & 31.8 \\
\hline 6.4 & 27.4 & 28.5 & 27.1 & 31.8 \\
\hline 5.2 & 30.7 & 29.6 & 29.1 & 32.0 \\
\hline 4.1 & 32.1 & 29.6 & 29.1 & 32.2 \\
\hline 3.2 & 32.1 & 29.7 & 29.1 & 32.2 \\
\hline
\end{tabular}


For all of the tested sensors, the smallest computed L1-norm value was obtained for the 3.1 numerical model. The other simulations (ranked from second to tenth) show L1-norm values with differences not exceeding 15\%. For the values of the L1-norm, both components have a similar share (41-56\% L1-norm for temperature and $59-44 \%$ L1-norm for pore pressure).

In the following iterations of the tested module, the comparison was performed in a window of 101 to 400 observations in size, and the average of all L1-norm values was calculated. Figure 8 depicts the averages for the ten-best numerical matches. In addition, the L1-norm difference can be correlated with the sensor locations: for sensors in the middle of the flood embankment, the L1-norm value is lower. The L1-norm values for the other sensors can be used to divide the sensors into two groups: those with significantly higher average L1-norm values (sensors UT6 and UT10), and all the rest. Also results shows the narrow confidence interval for mean, which proves only small discrepancies in the calculated values of the L1-norm in different window lengths for each numerical model.

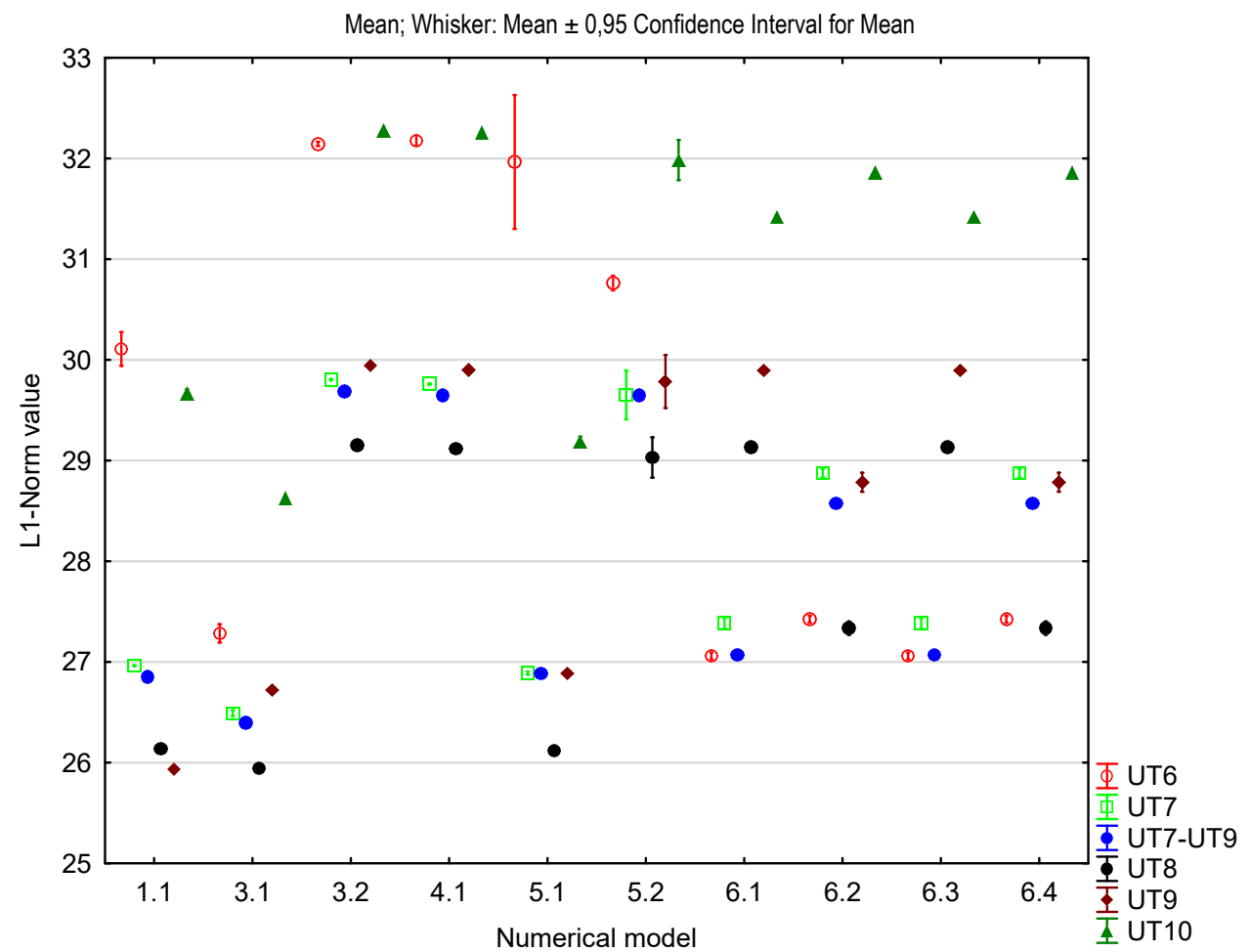

Figure 8. Average L1-norm value for all modelings and sensors. 
Analysis of L1-norm changes in the context of the aggregation window size shows its influence on the L1-norm value. For example, see Figure 9; this shows the values increasing slowly for UT7-UT10 and numerical model 3.1. For UT6, the values of the L1-norm increase slowly below a window size of $260(65 \mathrm{~h})$ and a faster increase above that size. This is connected with a higher value of the L1-norm for the temperature component and one anomaly value visible in Figure 7.

Also, the best match numerical model (3.1) was plotted with data from the experiment (see Figure 10). In the graphs are visible differences in the alignment, especially for the temperature models (which have not been validated yet). The temperature model is marked with a thick red line and pore pressure with a thicker green line.

The L1-norm values obtained for all of the ten best-matched numerical models are relatively low and show good matching of the numerical models to the experiment. The mean value of the L1-norm for one pair of observations (one time step: sum of the L1-norm for temperature and pore pressure) equals 0.3 .

L1-Norm for 3.1 Numerical model

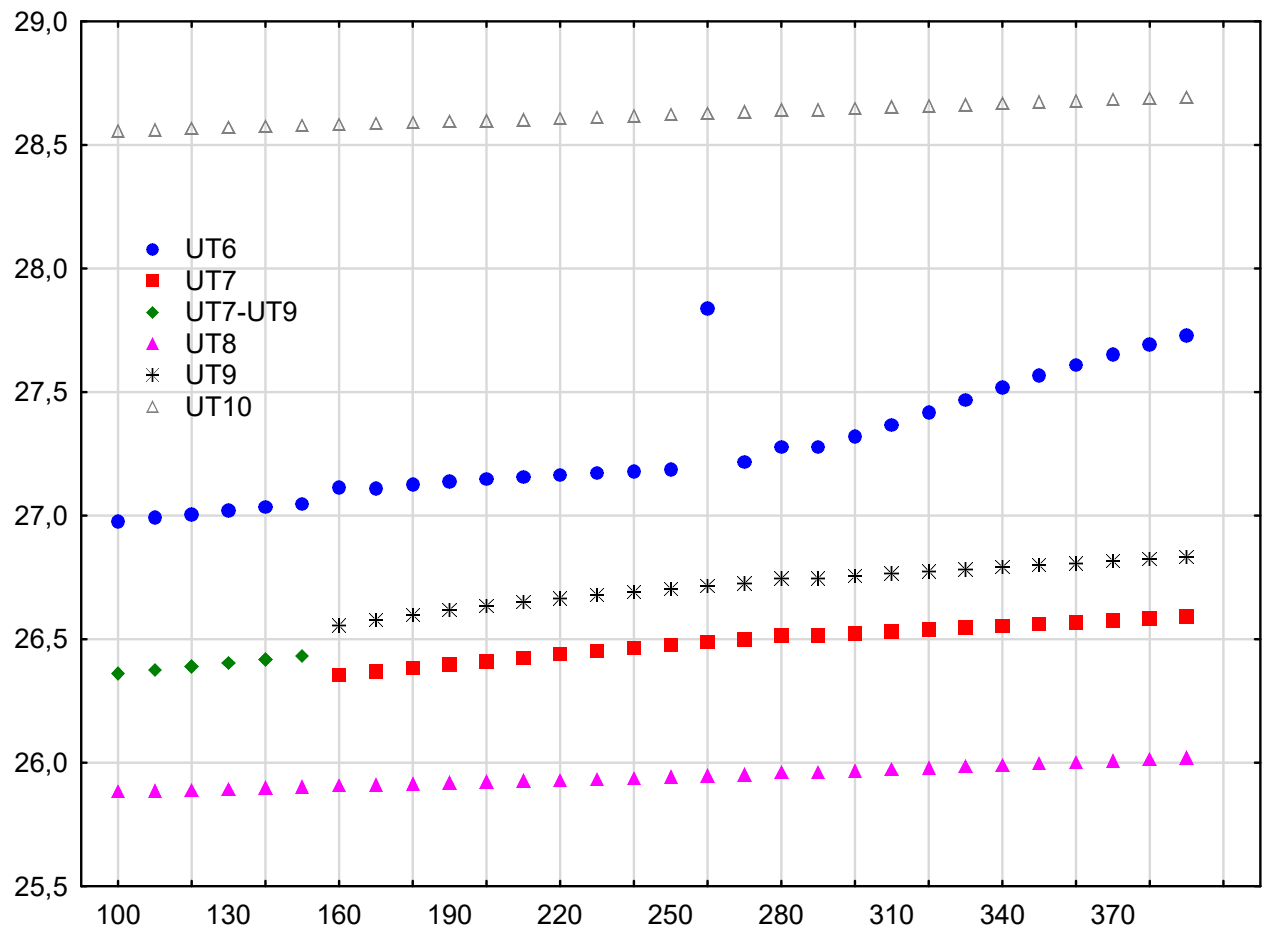

Figure 9. Changes of L1-norm values in context of aggregation window size for UT6-UT10. 

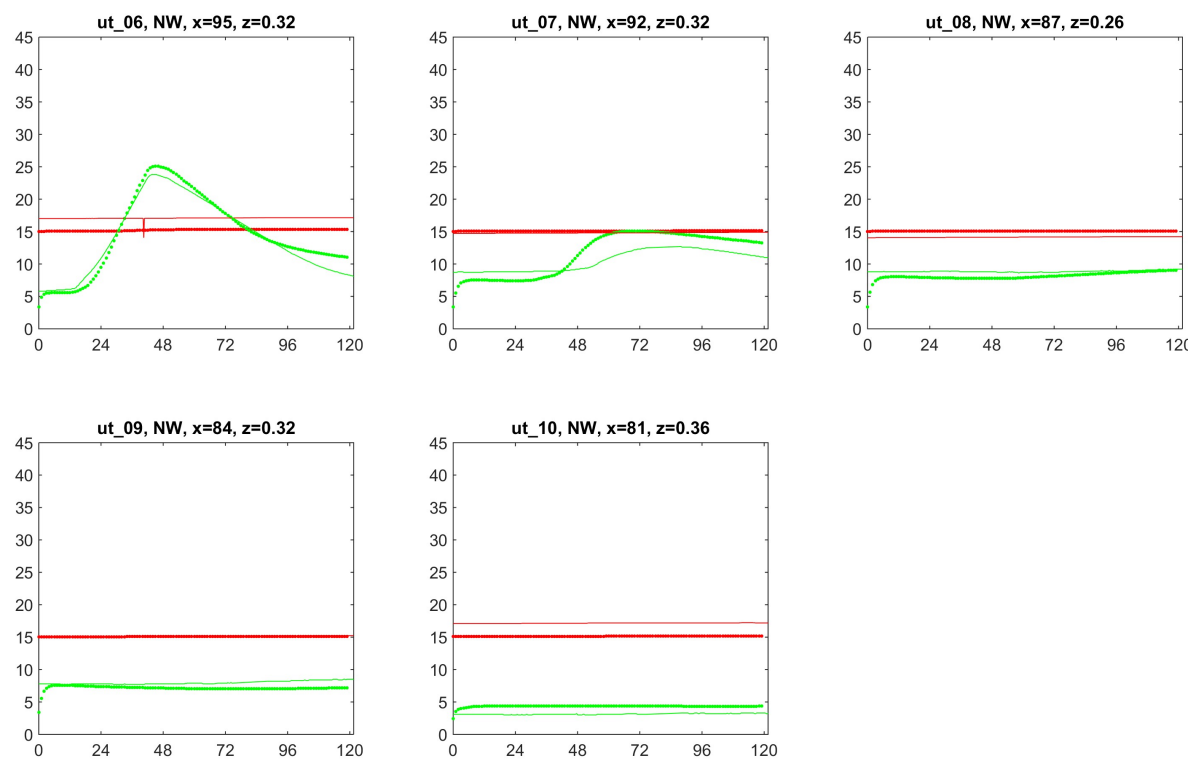

Figure 10. Comparison of numerical model 3.1 with data from experiment: red line - temperature $\left[{ }^{\circ} \mathrm{C}\right]$; green line - water pore pressure $[10 \mathrm{kPa}] ;$ line: thick - model, thin - experiment.

\section{Conclusion}

The model-driven module made it possible to choose the ten best-fitted numerical modelings for the real experiment that took place on the embankment between August 29, 2016, and September 3, 2016. The algorithm computed the L1-norm for all 17 numerical models and selected the 10 with the lowest L1-norm values. Nine of the selected models had a maximum water level of $3 \mathrm{~m}$. The best-fitting numerical models differed and correlated with the location of the sensors inside the embankment half cross-sections. The best match for all of the sensors was achieved for numerical model 3.1. Values of the L1-norm for sensors UT7-UT9 are 10\% lower than for the UT6 and UT10 sensors. The cause of the higher L1-norm values for the UT6 and UT10 sensors can be seen in graph 10 .

Finally, changing the aggregation window size (with the constant beginning at 9 p.m. on August 29, 2016) affects the L1-norm value. The L1-norm grows with the length of the window size. For UT6, the speed of growth is greater than for the other sensors.

\section{Acknowledgements}

The research presented in this paper was partially supported by the National Center for Research and Development (NCBiR) under Grant No. PBS1/B9/18/2013 and by the AGH grant no. 11.11.140.613. 


\section{References}

[1] Balis B., Brzoza-Woch R., Bubak M., Kasztelnik M., Kwolek B., Nawrocki P., Nowakowski P., Szydlo T., Zielinski K.: Holistic approach to management of IT infrastructure for environmental monitoring and decision support systems with urgent computing capabilities, Future Generation Computer Systems, vol. 79(1), pp. 128-143, 2018. https://doi.org/10.1016/j.future.2016.08.007.

[2] Balis B., Kasztelnik M., Bubak M., Bartynski T., Gubała T., Nowakowski T., Broekhuijsen J.: The UrbanFlood Common Information Space for Early Warning Systems, Procedia Computer Science, vol. 4, pp. 96-105, 2011. http://dx.doi. org/10.1016/j.procs.2011.04.011.

[3] Bukowska-Belniak B., Dwornik M., Pięta A., Leśniak A.: A 2D Model of Temperature Changes in Experimental Embankment, Measurement, Automation, Monitoring, vol. 61(6), pp. 233-236, 2015.

[4] Chuchro, M. Lupa M., Pięta A., Piórkowski A., Leśniak A.: A concept of time windows length selection in stream databases in the context of sensor networks monitoring. In: Bassiliades N., et al. (eds.): New Trends in Database and Information Systems II. Advances in Intelligent Systems and Computing, vol 312, pp. 173-183, Springer, 2014.

[5] Chuchro M., Franczyk A., Dwornik M., Leśniak A.: A Big Data processing strategy for hybrid interpretation of flood embankment multisensor data, Geology, Geophysics and Environment, vol. 42(3), pp. 269-277, 2016.

[6] Dwornik M., Krawiec K., Franczyk A., Leśniak A.: Numerical modelling of levee stability based on coupled mechanical, thermal and hydrogeological processes. In: E3S Web of Conferences, vol. 7 (2016) 0302, 2016.

[7] Dwornik M., Krawiec K., Pięta A., Leśniak A.: Numerical and experimental stability analysis of earthen levees. In: $A M G 2015$ : the 17th annual conference of the International Association for Mathematical Geosciences : Freiberg, Germany, September 5-13, 2015, vol. AMG 2015, short abstract: pp. 163-164, full paper: pp. 857-864, 2015.

[8] Habrat M., Lupa M., Chuchro M., Leśniak A.: A Decision Support System for Emergency Flood Embankment Stability, Procedia Computer Science, vol. 51, pp. 2957-2961, 2015.

[9] ISMOP: project website. http://www.ismop.edu.pl.

[10] Itasca Consulting Group: FLAC Fast Lagrangian Analysis of Continua and FLAC/Slope - User's Manual, 2001.

[11] Krawiec K., Bukowska-Belniak B., Leśniak A., Kessler D.: Analysis of the filtration processes in soil embankment based on numerical modelling and temperature measurements. In: FLOODrisk, vol. 7 (2016) 0302, 2016. http://www.e3s-conferences.org/articles/e3sconf/pdf/2016/ 02/e3sconf_flood2016_03018.pdf. 
[12] Krzhizhanovskaya V.V., Shirshov G.S., Melnikova N.B., Belleman R.G., Rusadi F.I., Broekhuijsen B.J., Gouldby B.P., Lhomme J., Balis B., Bubak M., Pyayt A.L., Mokhov I.I., Ozhigin A.V., Lang B., Meijer R.J.: Flood early warning system: design, implementation and computational modules, Procedia Computer Science, vol. 4, pp. 106-115, 2011. http://dx.doi.org/10.1016/j.procs. 2011.04 .012$.

[13] Lupa M., Leśniak A.: Geoportal jako narzędzie wspomagające prace geologiczno-inżynierskie na przykładzie projektu ISMOP, Roczniki Geomatyki, vol. 12(4), pp. 411-418, 2014.

[14] Pengel B.E., Krzhizhanovskaya V.V., Melnikova N.B., Shirshov G.S., Koelewijn A.R., Pyayt A.L., Mokhov I.I.: Flood early warning system: sensors and internet. In: IAHS Red Book N 35\%, Floods: From Risk to Opportunity, pp. 445-453, 2013.

[15] Pięta A., Dwornik M.: Analysis of boundary conditions offset for the accuracy of the numerical modeling of the levees. In: Proceedings of 14th International Multidisciplinary Scientific GeoConference (SGEM 2014), pp. 457-464, 2014.

[16] Pyayt A.L., Mokhov I.I., Kozionov A.P., Kusherbaeva V.T., Lang B., Krzhizhanovskaya V.V., Meijer R.J.: Data-driven modelling for flood defence structure analysis. In: Klijn F., Schweckendiek T. (eds.): Comprehensive Flood Risk Management: Research for Policy and Practice, p. 77, Taylor \& Francis Group, London 2012.

[17] Stanisz J., Borecka A., Leśniak A., Zieliński K.: Wybrane systemy monitorujące obwałowania przeciwpowodziowe - Selected levee monitoring systems, Przeglad Geologiczny, vol. 62, pp. 699-703, 2014.

[18] Stanisz J., Korzec K., Borecka A.: ISMOP Project (IT System of Levee Monitoring) as an example of integrated monitoring of levee, Geology, Geophysics and Environment, vol. 41(1), pp. 137-139, 2015.

\section{Affiliations}

\section{Monika Chuchro}

AGH University of Science and Technology, Faculty of Geology, Geophysics and Environmental Protection, al. A. Mickiewicza 30, 30-059 Kraków, Poland, chuchro@agh.edu.pl

Maciej Dwornik

AGH University of Science and Technology, Faculty of Geology, Geophysics and Environmental Protection, al. A. Mickiewicza 30, 30-059 Kraków, Poland

\section{Kamil Szostek}

AGH University of Science and Technology, Faculty of Geology, Geophysics and Environmental Protection, al. A. Mickiewicza 30, 30-059 Kraków, Poland

\section{Andrzej Leśniak}

AGH University of Science and Technology, Faculty of Geology, Geophysics and Environmental Protection, al. A. Mickiewicza 30, 30-059 Kraków, Poland

Received: 31.12 .2016

Revised: 31.05 .2017

Accepted: 22.08 .2017 